\title{
A postcontingency test of the effectiveness of reinforcement ${ }^{1}$
}

BARBARA H. WASIK. ${ }^{2}$ Education Improtement Program. Duke Uninersity, Durham, N.C. 27706

A test of the effectiveness of reinforcement outside the contingency condition was carried out with lever-pressing behavior using college students as Ss. When a more probable (reinforcing) response was made contingent upon a less probable (instrumental) response there was an increase in responding in the less probable response. This reinforcement effect, however, did not carry over into subsequent postcontingency conditions.

The two traditional methods for evaluating the effectiveness of reinforcement procedures have involved either an examination of the S's rate of responding during acquisition, or an examination of some measure of resistance to extinction. Schaeffer (1962) has proposed an alternative method for evaluating the effectiveness of reinforcement in which both the reinforcing (the more probable response) and the instrumental response (the less probable response) are made freely and concurrently available to the $S$ in a postcontingency test. The residual effects of reinforcement are evaluated comparing the postcontingency rate of the less probable response with the precontingency rate of the less probable response. If reinforcement does have a residual effect on the instrumental response which carries beyond the reinforcement contingency, the test that Schaeffer proposed permits evaluation of the postcontingency effect. By way of contrast, the two traditional methods for evaluating the effectiveness of reinforcement involve either a condition in which reinforcement is contingent upon the completion of a response requirement or an extinction condition in which reinforcement is withheld by the $\mathrm{E}$.

Using an instrumental licking response and a reinforcing running response with rats as Ss, Schaeffer (1962) employed the pre- and postcontingency baseline procedure just described and obtained an increase in the low rate instrumental response in the contingency condition. No systematic increments in the low rate response in the postcontingency test were found, suggesting that the effects of reinforcement may be confined totally to the reinforcement contingency. The main purpose of this experiment was to test for residual reinforcement effects with human lever-pressing behavior by the described postcontingency procedure. The experimental design to arrange the contingency condition was based upon Premack's generalization of reinforcement which states that for any two responses, the more probable response will reinforce the less probable response (Premack, 1965). This design, as described by Schaeffer, Hanna, \& Russo (1966), requires a pretest to assess the probability level of two responses, and a contingency condition in which the more probable response is made contingent upon the less probable response.

$$
\text { METHOD }
$$

The 12 Ss for this experiment were male and female undergraduate students who were volunteers from the general psychology classes at Florida State University. Each S was tested separately. The $S$ was conducted into the test room, seated in front of the test console, and given the following instructions: "Your task is to try to earn as many points as possible. You may press any lever with either hand, but you are not to press two levers simultaneously. You will be told when you may begin. When you hear a rap on the door, you are to stop, and when you hear another rap, you may begin again."
The apparatus consisted of a Bud CU-2107 Minibox in which a Sodeco counter was mounted between two Switchcraft type 61324 telephone levers. One of the two levers was programmed on $C R F$; the other was programmed on FR 5. A red jewel light above each lever served as discriminative stimulus and was illuminated when depression of the lever below it could result in points for the Ss.

In the precontingency, operant level tests, and in the noncontingency trials, both responses were freely available to the Ss and both lights were illuminated. Each depression of the CRF lever produced one point on the S's counter, and five depressions of the FR 5 lever produced one point on the S's counter.

In the contingency sessions, completion of a response requirement on an instrumental response made the contingent response available for a set period of time, the contingent time (CT). Throughout this experiment the CT was $10 \mathrm{sec}$.

Four trials were given in which both levers were freely and concurrently available to the Ss. Over these operant trials responding on the CRF lever reached a mean rate of over four responses per second while responding on the FR lever dropped essentially to zero. Thus, in the contingency conditions, the more probable CRF response was made contingent upon the less probable FR response. In the contingency condition, completion of a requirement on the FR lever made the CRF lever available to the $S$ for $10 \mathrm{sec}$ during which time he could earn one point for each lever press. Each five depressions of the FR 5 lever produced one point on the $S$ 's counter independently of the availability of the CRF lever.

Each $S$ was given a total of eight trials in which the CRF lever was contingent upon the FR 5 lever. Each contingency condition was followed by a noncontingency condition in which both levers were concurrently available and the Ss could choose between the levers. All trials were $5 \mathrm{~min}$ in duration with a $1-\mathrm{min}$ intertrial interval.

\section{RESULTS}

The results of this experiment are summarized in Fig. 1, where the mean number of responses the $12 \mathrm{Ss}$ emitted on each lever are shown as a function of the experimental conditions. Mean response rates on the two levers in the precontingency trials, in which both levers were freely and

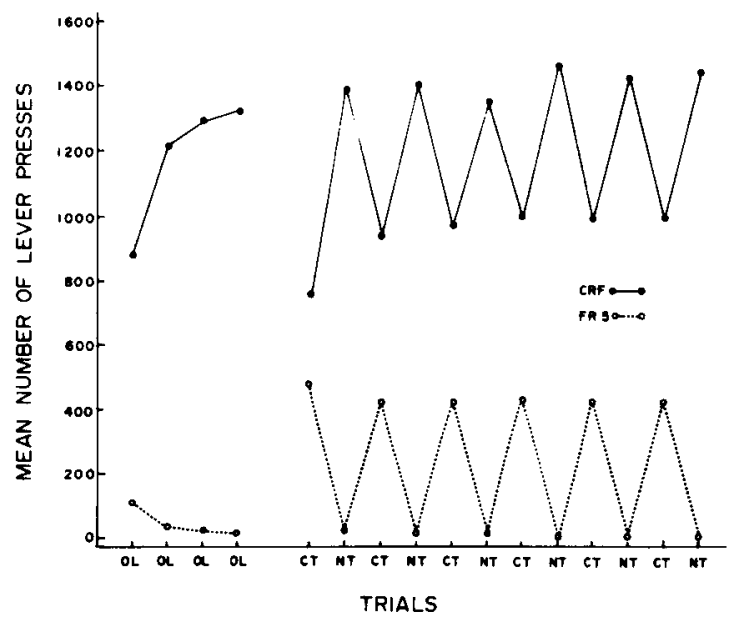

Fig. 1. Mean number of lever presses per trial for alternating contingency and noncontingency conditions for the CRF and FR levers. 
concurrently available, illustrated that Ss initially sample both levers, but obviously quickly limited their responding to the CRF lever.

When the first contingency was introduced, in which the CRF lever was contingent upon the FR lever, responding on the FR lever increased while responding on the CRF lever decreased in comparison with the precontingency response rates. In the subsequent noncontingency trial, rate of responding on the $F R$ lever dropped to almost zero and rate of responding of the CRF lever increased to four or five responses per second. The pattern of responding obtained in the first contingency and the first noncontingency conditions persisted throughout the experiment.

The results of an analysis of variance indicated that responding on the CRF lever in the contingency conditions was significantly different from the responding on the CRF lever in the noncontingency conditions $(F=29.72, \mathrm{df}=1 / 22$, $p<.01)$. Responding on the $F R$ lever in the contingency conditions was significantly different from responding on the $F R$ lever in the noncontingency conditions $(F=86.44$, $\mathrm{df}=1 / 22, \mathrm{p}<.01$ ).

There was no significant change in rate of responding on the CRF lever across the successive noncontingency sessions $(F=1.15, d f=5 / 72, p>.05)$. Furthermore, the results of a $t$ test indicated no significant difference between CRF lever responding on the noncontingency trials and CRF lever responding on the last two precontingency trials $(t=2.07$, $\mathrm{df}=11, \mathrm{p}>.05$ ). Thus, one can conclude that when the CRF lever became freely available, the precontingency rate of responding on the CRF lever was recovered.

There was no significant change in responding on the FR lever across the contingency sessions $(F=.93, \mathrm{df}=5 / 72$, $p>.05)$ or for the successive noncontingency conditions $(\mathrm{F}=.01, \mathrm{df}=5 / 72, \mathrm{p}>.05)$. There was, however, a significant difference in responding on the CRF lever across contingency trials $(F=6.00, d f=5 / 72, p<.01)$. The results of the Duncan multiple range test indicated that the first contingency trial differed significantly from each of the last four contingency trials, but not from the second contingency trial. Furthermore, there were no significant differences among the last five contingency trials. This indicates that the Ss very quickly became efficient in earning points on the CRF lever across the contingency trials.

\section{DISCUSSION}

Based on the results of the present study, it is obvious that the increment afforded the instrumental response in the contingency conditions did not carry over into the noncontingency conditions. The results of the present experiment may be contrasted with data obtained in studies in which resistance to extinction is the measure by which the effects of previous reinforcement contingencies are evaluated. Typically in extinction, the probability of occurrence of the instrumental response is greater than it had been in the operant level condition. It should be recognized, however, that the reinforcing response is not available to the $S$ in extinction, and that across successive extinction sessions, the rate of the instrumental response decreases essentially to its prereinforced level (Kimble, 1961). In this context, extinction may not be an unbiased method for examining the residual effects of reinforcement, but rather may be a method for examining the ability of the $S$ to discriminate reinforcement conditions from nonreinforcement conditions. The fact that resistance to extinction does decrease to somes limiting value across successive extinction sessions, coupled with the results of the present study, may indicate that the effects of reinforcement may be confined to the reinforcement contingency.

Further confirmation of this interpretation is afforded not only by the Schaeffer (1962) study described above, but also by the following studies. Holstein \& Hundt (1965), using intracranial self-stimulation and licking responses in rats, found that the increased instrumental responding which occurred in the contingency conditions was not maintained in postcontingency tests. Baer (1962), using children as Ss, and Ayllon \& Azrin (1965), using psychotic patients as Ss, have also obtained results that are consistent in showing that the reinforcement effect obtained in the contingency condition did not occur in the postcontingency condition.

The present study and the studies described above indicate that when the contingency between two responses is removed and reinforcement is freely available, no residual postcontingency effects of reinforcement are obtained. In extinction, the initial increased responding on the instrumental response suggests that the effectiveness of reinforcement may hold beyond the contingency. The disparate results from the two methods do suggest that the effectiveness of reinforcement may be confined totally to the contingency. Further research is needed to determine the lack of comparability of the two methods for examining the residual effects of reinforcement.

\section{REFERENCES}

AYLLON, T., \& AZRIN, N. H. The measurement of reinforcement of behavior of psychotics. Journal of the Experimental Analysis of Behavior, 1965, 8, 357-383.

BAER, D. B. Laboratory control of thumbsucking by withdrawal and representation of reinforcement. Journal of the Experimental Analysis of Behavior, $1962,5,525-528$.

HOLSTEIN, S. B., \& HUNDT, A. G. Reinforcement of intracranial self-stimulation by licking. Psychonomic Science, 1965, 3, 17-18.

KIMBLE, G. C. Hilgard and Marquis' conditioning and learning. New York: Appleton-Century-Crofts, 1961.

PREMACK, D. Reinforcement theory. In D. Levine (Ed.), Nebraska symposium on motivation. Lincoln: University of Nebraska Press, 1965.

SCHAEFFER, R. W. Contributions of the operant level of the instrumental response to the reinforcement relation. Unpublished doctoral dissertation, University of Missouri, 1962.

SCHAEFFER, R. W., HANNA, B., \& RUSSO, P. Positive reinforcement: A test of the Premack theory. Psychonomic Science, 1966, 4, 7-8. NOTES

1. This study was submitted as part of the author's dissertation to the graduate school, Florida State University, Tallahassee, Florida. The research was supported by USPHS Research Grant No. MH12025 from the National Institute of Mental Health. Special appreciation is extended to Robert W. Schaeffer, the author's major professor, for his assistance and support.

2. Associate Director of Research and Evaluation, Education Improvement Program, Duke University, Durham, North Carolina. 